ИЗВЕСТИЯ АКАДЕМИИ НАУК ЭСТОНСКОЙ ССР. ТОМ 21

ХИМИЯ - ГЕОЛОГИЯ. 1972, № 2

удК $552.521: 551.733 .1(474.2)$

Э. КИВИМЯГИ, А. ЛООГ

\title{
ОСНОВНЫЕ ТИПЫ ТЕКСТУР ГРАПТОЛИТОВЫХ АРГИЛЛИТОВ МЕСТОРОЖДЕНИЯ ТООЛСЕ
}

В ходе детальных геолого-разведочных работ на месторождении фосфоритов Тоолсе проводилось изучение вскрышных пород с целью выяснения возможностей их комплексной эксплуатации. Получены новые данные о строении тюрисалуской пачки граптолитовых аргиллитов (синонимы: диктионемовые сланцы, диктионемовые аргиллиты) пакерортского (цератопигевого ?) горизонта (Кальо, Кивимяги, 1970), в частности об их текстурах.

Литологический облик пачки граптолитовых аргиллитов в пределах месторождения Тоолсе очень пестрый. В пачке аргиллитов встречаются прослои сероватого кварцевого материала алевритовой размерности и белого аморфного кремнистого материала со спикулями кремневых губок. Часто с этими же прослоями связаны конкреции и скопления пирита и антраконита. Мощность прослоев очень изменчивая (от 1,0 до 6,0 cм, реже более), и они имеют сложную текстуру (см. фиг. 1,2 и 3 ). В настоящей работе основное внимание обращено на текстуры аргиллитов, т. е. частей разреза тюрисалуской пачки, где преобладают темнокоричневые уплотненные глинистые породы, пропитанные органическим веществом.

В разрезе рассматриваемой пачки выделяются слои аргиллита с разными текстурными особенностями. В основном текстуры аргиллитов связаны со слоистостью. Эти текстуры являются первичными и отражают особенности среды осадконакопления. Встречаются также текстуры, образовавшиеся в процессах позднего диагенеза или катагенеза осадка. Их можно условно назвать вторичными. Часго очень трудно определить. является ли текстура первичной или вторичной.

Все изученные текстуры аргиллитов можно подразделить на следующие основные типы.*

\section{I. Макротекстуры}

1) Горизонтальнослоистая текстура (фиг. 4) обусловлена послойным распределением в разрезе пачки материала разной размерности. В аргиллите встречаются главным образом алевролитовые прослои мощностью от 1 мм до нескольких сантиметров. Горизонтальная слоистость аргиллита образовалась в основном уже в стадии седиментации в результате периодического увеличения привноса алевритового материала в бассейн.

* Классификация текстур по М. Викуловой (1957) с дополнениями авторов. 
2) Однородная или сплошная текстура (фиг. 5) наблю. дается у равномерно окрашенных аргиллитов, которые почти не содержат частиц алевритовой размерности (или же эти частицы равномерно рассеяны в породе) и имеют одинаковую степень уплотнения. Эта текстура образовалась при медленном накоплении в основном пелитовых частиц.

3) Линзовидн а я текстура (фиг. 6 и 7 ) характеризуется изгибанием прослоев алевролита и слойков аргиллита вокруг линзовидных скоплений белого аморфного кремнистого материала, которые в ходе уплотнения осадка в стадии раннего диагенеза сохранили свой объем (фиг. 6), или же она образовалась в стадии позднего диагенеза, когда растущие конкреции антраконита или пирита раздвигали прослойки вмещающей пелитовой породы (фиг. 7). Последнее по существу является вторичным изменением первоначальной горизонтальнослоистой текстуры.

4) Неправильная текстура (фиг. 8 и 9) выражена беспорядочным расположением или прерыванием прослоек породы. Она образовалась в стадии раннего диагенеза в результате оползневых явлений (фиг. 8) или в стадии позднего диагенеза в результате быстрого роста конкреций пирита или антраконита (фиг. 9).

\section{II. Микротекстуры}

Микротекстуры отличаются от выделенных макротекстур не только по размерам, но и некоторыми другими характерными признаками. Это обстоятельство позволяет выделить ряд самостоятельных типов микротекстур граптолитовых аргиллитов. В зависимости от вещественного состава пород целесообразно рассматривать текстуры в чистых аргиллитах (1 и 2 типы) и в аргиллитах с алевритовой примесью (3, 4 и 5 типы).

1) Ориентированная микротекстура (фиг. 10) характе. ризуется параллельным наслоению расположением удлиненных глинистых минералов, которые обычно пропитаны органическим веществом. При этом глинистые минералы являгтся единственными породообразую-

Фиг. 1-9: макротекстуры аргиллитов, увеличение $\times 0,75$.

1 - Прослой алевролита с многочисленными конкрециями антраконита и пирита. Скв. Тоолсе 533 , гл. 27,80 м, комплекс $B$.

2 - Прослой алевролита с конкрецией кальцита и с белым аморфным кремнистым материалом. Скв. Тоолсе 811 , гл. $15,50 \mathrm{M}$, комплекс $B$.

3 - Мелкозернистый песчаник. Более однородные участки лучше сцементированы (пиритовый или кальцитовый цемент базального типа); белые участки - аморфный кремнистый материал. Скв. Тоолсе 519 , гл. $21,25-21,30$ м, комплекс С.

4 - Горнзонтально-слоистая текстура граптолитовых аргиллитов. Темная порода аргиллит, серая - алевролит, белая - аморфный кремнистый материал. Скв. Тоолсе 811, гл. $15,45 \mu$, комплекс $B$.

5 - Однородная текстура ғраптолитовых аргиллитов. Скв. Тоолсе 515, гл. 32,85 м, комплекс $B$.

6 - Линзовидная текстура граптолитовых аргиллитов. Темная порода - аргиллит, серая - алевролит, белая - аморфный кремнистый материал. Скв. Тоолсе 804, гл. 14,55 м, комплекс $B$.

7 - Линзовидная текстура граптолитовых аргиллитов. Темная порода - аргиллит, серая - пиритовая конкреция, белая - аморфный кремнистый материал. Скв. Тоолсе 515 , гл. 33,20 м, комплекс $B$.

8 - Неправильная текстура граптолитовых аргиллитов. Темная порода - аргиллит, серая - алевролит, белая - аморфный кремнистый матернал. Скв. Тоолсе 515 , гл. $32,60 \mathrm{м}$, комплекс $B$.

9 - Неправильная текстура граптолитовых аргиллитов. Темная порода - аргиллиг, серая - конкреции антраконита, белая - аморфный кремнистый материал. Скв.

Тоолсе 411 , гл. 28,90 м, комплекс $B$. 

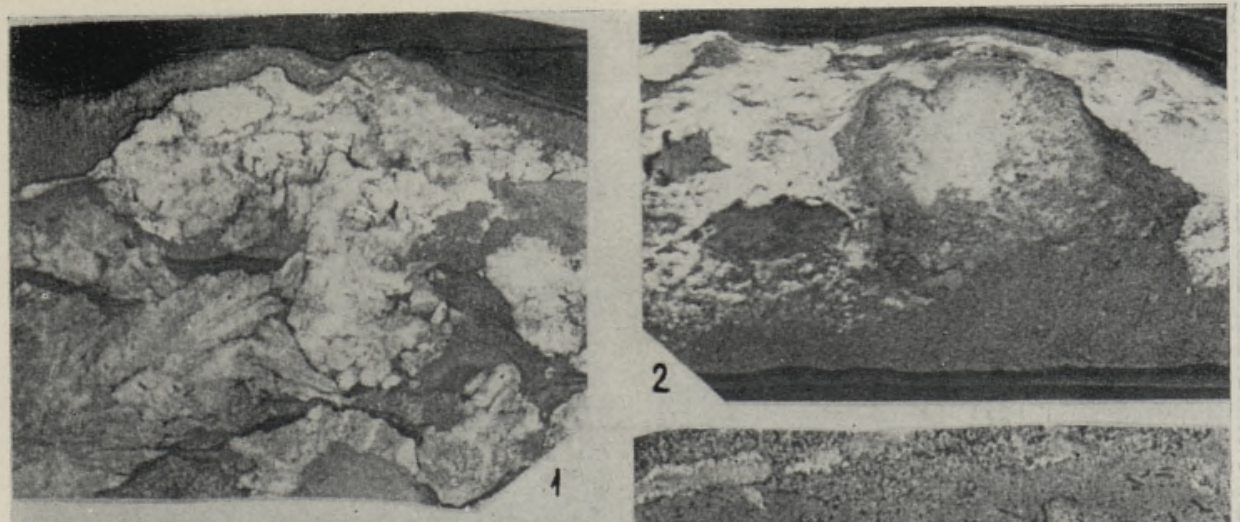

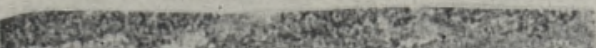

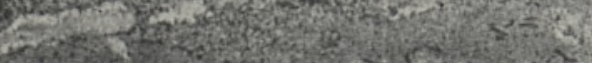

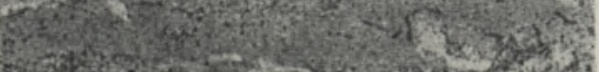

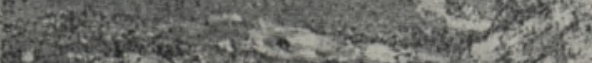

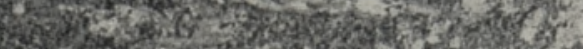

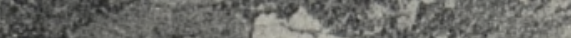

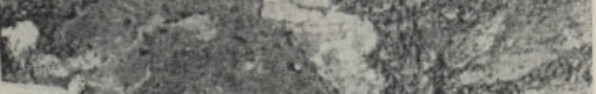

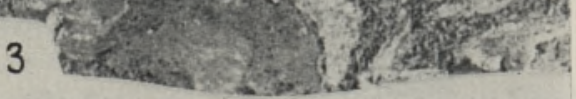

\section{4}
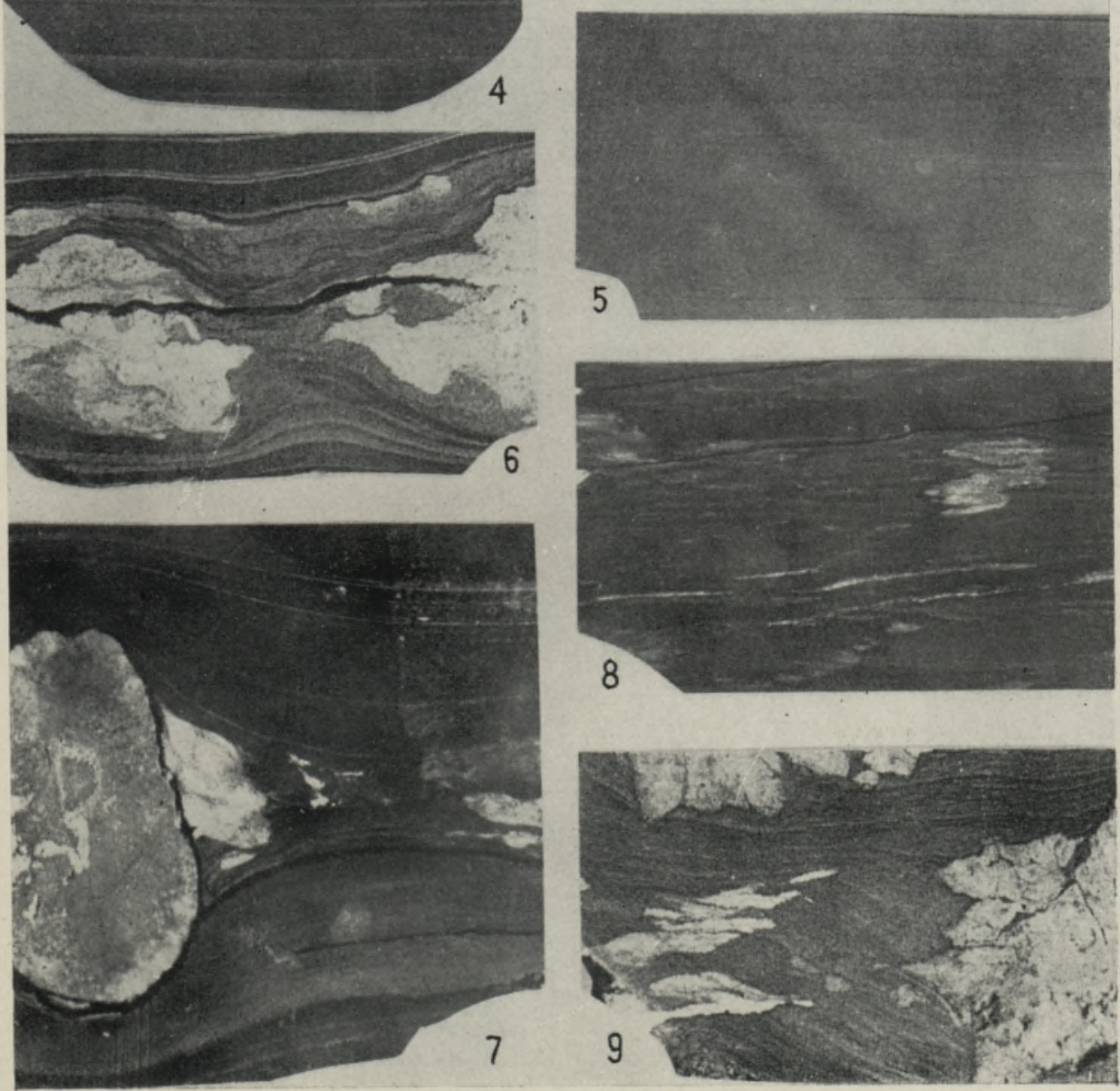


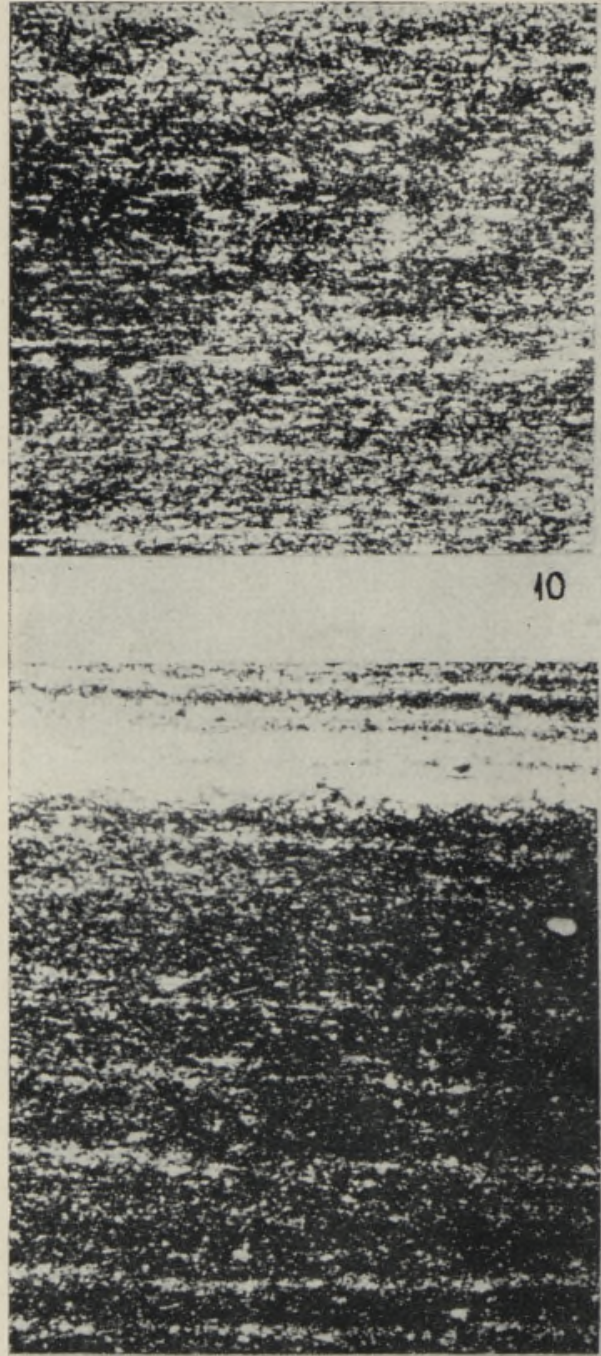

10

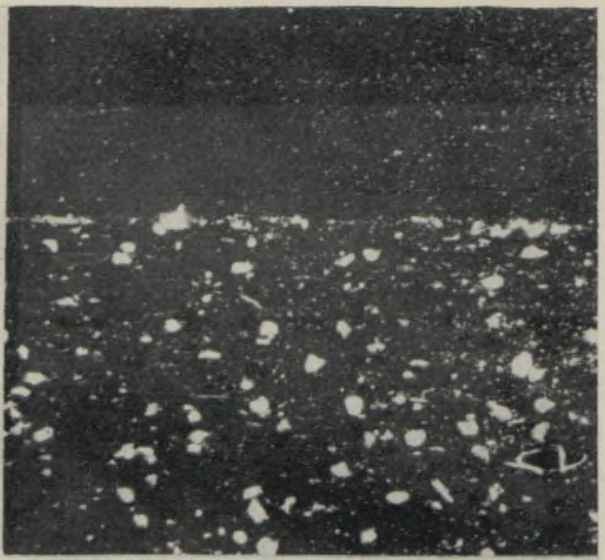

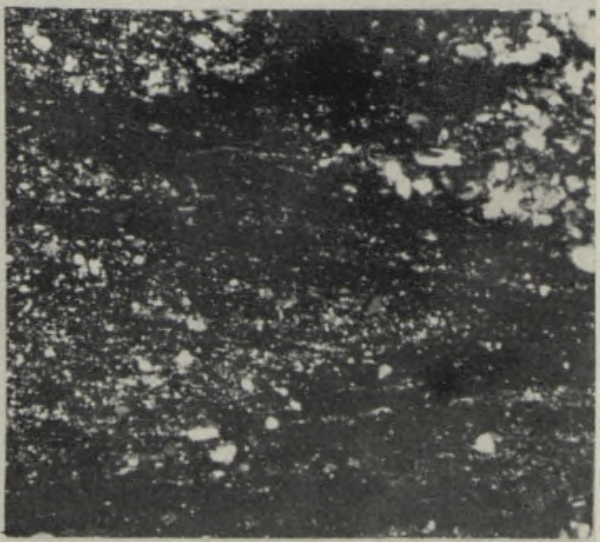

13
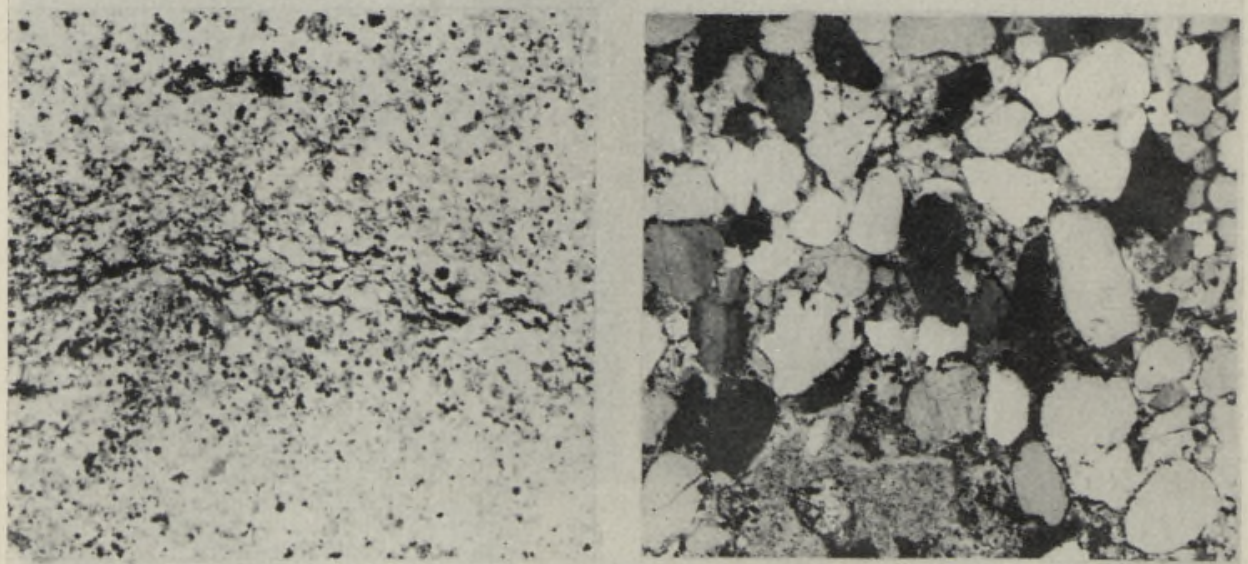
щими минералами. Ориентированная микротекстура образовалась при самом медленном накопленин пелитового материала в условиях спокойного бассейна.

2) Беспорядочная микротекстура (фиг. 11) характеризуется расположением в породе глинистых минералов без всякой ориентации. Другие минералы почти отсутствуют. Әта текстура образовалась при быстром накоплении пелитовых частиц.

3) Горизонтальнослови тая микротекстура (фиг. 12) выражается в расположении кварцевых частиц алевритовой размерности горизонтальными непрерывными рядами мощносгью до 1 мм в основной пелитовой массе. Горизонтальная микрослоистость образовывается в ходе осадконакопления, реже - в результате перераспределения в осадке частиц разных размеров в стадии раннего диагенеза.

4) Гнездовидная микротексту р а (фиг. 13) образовалась в стадии осадконакопления за счет неравномерного распределения или гнездовидного скопления алевритовых частиц кварца в основной пелитовой массе.

5) Р авноернорассеянная микр о тек с т р а (фиг. 11) характеризуется отдельными частицами кварца алевритовой размерности, равномерно рассеянными в основной пелитовой массе, где глинистые минералы обычно не имеют преимущественной ориентированности. Эта текстура образуется главным образом в стадии осадконакопления в результате равномерного привноса терригенного материала в бассейн и равномерного распределения его в осадке.

Кроме приведенных выше основных типов макро-и микротекстур граптолитовых аргиллитов месторождения Тоолсе, существует еще множество подтипов и переходных типов текстур.

Вертикальный разрез граптолитовых аргиллитов месторождения средней мощностью 1,4 м подразделяется снизу вверх (см. рисунок) по своим структурным и текстурным особенностям на четыре слоя (комплекса): $A, B, C$ и $D$ (Кивимяги,
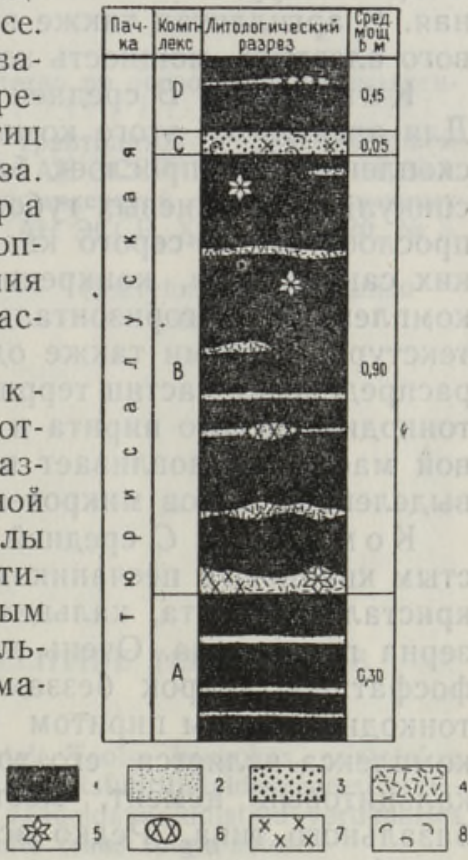

Подразделение тюрисалуской пач ки граптолитовых аргиллитов месторождения Тоолсе.

I - граптолитовые аргиллиты; 2 алевролит; 3 - песчаник; 4 - ғелы аморфный кремнистый материал со спикулями кремневых губок; 5 -конкрецин антраконита; $6-$ конкрешни пирита: 7 - пиритный цемепт; 8 - обломки фосфатных створок беззамковых брахнопод. Теедумяэ, 1971).

Фиг. 10-15: микрстекстуры аргиллитов, увеличение $\times 30$; без анализатора.

10 - Ориентированная микротекстура граптолитовых аргиллитов. Шлиф Д-1302, скв. Тоолсе 695 , гл. 18,75 м, комплекс Д.

11 - Беспорядочная микротекстура (верхняя часть) и равномернорассеянная микротекстура (нижняя часть). Шлиф Д-1331, скв. Тоолсе 804 , гл. 14,85 , комплекс $B$. 12 - Горизонтальнослоистая микротекстура. Шлиф Д-1320, скв. Тоолсе 804 , гл. 14,30 м, комплекс $B$.

13 - Гнездовидная микротекстура. Шлиф Д-1310, скв. Тоолсе 695, гл, 19,45 м, комплекс $B$. 14 - Белый аморфный кремнистый материал со спикулями кремневых губок. Шлиф Д-1306, скв. Тоолсе 695 , гл. 19,15 м, комплекс $B$.

15 - Мелкозернистый песчаник с обломками фосфатных створок брахиопод (темные). Шлиф Д-1318, скв. Тоолсе 804, гл. 14,20 м, комплекс С.

4 ENSV TA Toimetised $\mathrm{K} * \mathrm{G}-21972$ 
Комплекс $A$ средней мощностью 0,3 м представлен в основном горизонтальнослоистыми темно-коричневыми аргиллитами, часто имеющими также однородную текстуру. Основная пелитовая масса аргиллитов слагается тонкодисперсными, зачастую ориентированными частицами глинистых минералов: гидрослюд (85-95\%) и хлорита (5-15\%), которые имеют коричневый цвет за счет примеси органического вещества, количество которого достигает в породе $19 \%$. Такой характер и минералогический состав аргиллитов сохраняется во всем разрезе тюрисалуской пачки. В рассматриваемом комплексе встречаются все выделенные типы микротекстур, но особенно горизонтальнослонстая и равномернорассеянная. В аргиллитах также встречаюгся прослойки светло-серого кварцевого алеврита, мощность которых иногда достигает $6 \mathrm{c \mu}$.

Комплекс $B$ средней мощностью 0,9 м имеет сложное строение. Для аргиллитов этого комплекса характерно присутствие линзовидных скоплений или прослоек белого аморфного кремнистого материала со спикулями кремневых губок (фиг. 14). Встречается также множество прослоев светло-серого кварцевого алевролита мощностью до несколь ких сантиметров, конкреции пирита и антраконита. Вследствие этого комплекс имеет горизонтальнослсистую, неправильную или линзовидную текстуру, местами также однородную текстуру. Количество и характер распределения частиц терригенных минералов, главным образом кварца, тонкодисперсного пирита и редких оондов фосфатов в основной пелитовой массе обусловливает присутствие в аргиллитах комплекса $B$ всех выделенных типов микротекстур.

Комплекс $C$ средней мощностью 0,05 м представлен мелкозернистым кварцевым песчаником. В нем между зернами кварца встречаются крйсталлы пирита, кальцита, доломита, отдельные ооиды фосфатов и зерна глауконита. Очень характерным является присутствие обломков фосфатных створок беззамковых брахиопод, которые импрегнированы тонкодисперсным пиритом (фиг. 15). Вторым характерным признаком комплекса является его хорошая цементация. Преобладает базальный кальцитовый цемент, местами пиритовый регенерационный цемент базального типа. Редко встречаются линзовидные прослойки белого аморфного кремнистого материала (фиг. 3). Песчаник имеет линзовидную и пятнистую текстуру.

K о м п л е к с $D$ средней мощностью 0,15 м имеет однородный литологический характер. Он сложен темно-коричневыми аргиллитами, которые обычно обладают соответствующей однородной текстурой. Местами наблюдаются тонкие (до $4-5$ мм) прослойки кварцевого алевролита, которые придают аргиллитам горизонтальнослоистую текстуру. Иногда с этими прослойками связаны пластовндные конкреционные тела пирита, которые обусловливают линзовидную текстуру аргиллитов. Самым характерным для аргиллитов комплекса является ориентированная микротекстура. Иногда встречаются как беспорядочная, так и горизонтальнослонстая микротекстуры.

Небезынтересно отметить, что в вертикальном разрезе граптолитовых аргиллитов месторождения Тоолсе не наблюдается ритмического повторения типов текстур, как это описывалось в некоторых других местах Северо-Восточной Эстонии.

На основе изучения литологического состава граптолитовых аргиллитов и их макро- и микротекстур можно сделать вывод, что граптолитовые илы в целом накапливались очень медленно и в относительно мелководной части эпиконтинентального моря, где влияние волнения и течений на перераспределение материала было ослаблено или периодически вообще отсутствовало. Подробное изучение разреза граптолитовых 
аргиллитов месторождения Тоолсе показывает, что условия образования отдельных комплексов имели некоторые существенные различия. Так, можно утверждать, что условия осадконакопления граптолитовых илов начиная с комплекса $A$ становились все более и более изменчивыми до полного прекращения накопления глинистого материала в комплексе $C$. Комплекс $D$ образовался опять при спокойных условиях осадконакопления. Самые большие диа- и катагенетические изменения (образование конкреций пирита и антраконита) происходили в осадках комплекса $B$.

\section{ЛИ И Е Р А Т Р Р А}

В и кулов а М. Ф. и др. 1957. Методическое руководство по петрографо-минералогиKO ческому нзучению глин. М.

Кальо Д., Ки в и м г и Э. 1970. О распределении граптолитов в диктионемовюм сланще Эстонии и разновидности его фаций. Изв. АН ЭССР, Хим. Геол., 19, № 4. К и вимяги Э., Т е едум яэ А. 1971. Результаты комплексной оценки вскрышных пород месторождения фосфоритов Топлсе. Изв. АН ЭССР, Хим. Геол., 20, № 3.

Управление геологии

Совета Министров Эстонской ССР

Тартуский государственный университет
Поступила в редакщию 9/VI 1971

\section{E. KIVIMÄGI, A. LOOG}

\section{TOOLSE LEIUKOHA GRAPTOLIITSETE ARGILLIITIDE TEKSTUURIDE PÕHITUUBID}

Tuginedes argilliitide litoloogilise uurimise tulemustele Toolse leiukohas, eristatakse nende makro- ja mikrotekstuuride põhitüübid. Esitatakse eri tekstuuritüüpide geneesi erinevused ja iseloomustatakse eri tekstuuritüüpide levikut vaadeldava kihistiku vertikaalses läbilōikes, mis võimaldab anda üldpildi uuritavate kivimite tekke tingimustest.

\section{E. KIVIMÄGI, A. LOOG}

\section{THE MAIN STRUCTURAL TYPES OF GRAPTOLITIC ARGILLITES OF THE TOOLSE DEPOSIT}

A lithological study of the graptolitic argitlites in the deposit of Toolse has enabled us to define the following types of macro- and microstructure of those argillites.

Macrostructures: horizontal-bedded, homogeneous, lens-shaped, irregular; microstructures: oriented, random, horizontal-bedded, nested, equally spaced.

It has been stated that there are differences in the genesis of the above-mentioned structural types as well as in the nature of their distribution in the section of the deposit, i. e, within the complexes $A, B, C$ and $D$. It is assumed that graptolitic muds, on the whole, were formed under very calm conditions of sedimentation. 